\title{
Alternative donor peripheral blood stem cell transplantation for the treatment of high-risk refractory and/or relapsed childhood acute leukemia: a randomized trial
}

Binglei Zhang ${ }^{1,2}$, Jian Zhou ${ }^{3}$, Fengkuan Yu ${ }^{3}$, Tianxin Lv ${ }^{2,3}$, Baijun Fang ${ }^{3}$, Dandan Fan ${ }^{4}$, Zhenyu $\mathrm{Ji}^{4^{*}}$ and Yongping Song ${ }^{3^{*}}$

\begin{abstract}
Background: The high-risk refractory and/or relapsed (R/R) childhood acute leukemia prognosis is poor, and allogeneic stem cell transplantation (allo-HSCT) is the most prudent treatment modality. However, there are limited matched sibling donors (MSDs), and alternative donors (ADs) are the main source for allo-HSCT. Thus, we evaluated the clinical efficacy of AD peripheral allo-HSCT for treating high-risk R/R childhood acute leukemia.

Methods: We assessed 111 children who underwent allo-HSCT at the Affiliated Cancer Hospital of Zhengzhou University between October 2006 and July 2019. The patients were divided in the MSD and AD groups, and their clinical characteristics, complications, and survival rates were compared.

Results: The cumulative incidences of Epstein-Barr virus and cytomegalovirus infections were significantly higher in the AD than in the MSD group $(P<0.001)$; however, the recurrence and mortality rates were significantly higher in the MSD than in the AD group ( $P<0.05)$. Furthermore, the 5 -year disease-free (DFS) $(65.2 \%$ vs. $43.3 \%, P=0.033)$ and overall survival (OS) rates (71.6\% vs. $53.8 \%, P=0.053)$ were significantly higher in the $A D$ than in the MSD group. In the AD group, the grade II-IV acute graft-versus-host disease (aGVHD), donor-recipient ABO compatibility, conditioning regimen, and CMV infection affected the 5-year OS. The grade II-IV aGVHD also affected the 5-year DFS; however, only the donor-recipient ABO compatibility affected the 5-year DFS. The donor MSD (HR: 2.035, 95\% confidence interval $[\mathrm{CI}] 1.057-3.920, P=0.034)$ and the grade II-IV aGVHD (HR: 2.914, 95\% Cl 1.261-6.736, $P=0.012)$ affected the 5-year DFS of childhood acute leukemia after allo-HSCT, and the grade II-IV aGVHD (HR: 3.016, 95\% Cl 1.217-7.473, $P=0.017$ ) affected the 5-year OS. Moreover, the donor source (HR: 2.836, 95\% Cl 1.179-6.823, $P=0.020$ ) and grade II-IV aGVHD (HR: $3.731,95 \% \mathrm{Cl} 1.332-10.454, P=0.012$ ) were independent predictors of the 5-year DFS, while the latter (HR: 3.524 , $95 \% \mathrm{Cl} 1.310-10.988, P=0.030$ ) was an independent predictor of the 5 -year OS.
\end{abstract}

Conclusions: AD-PBSCT was effective for high-risk R/R childhood leukemia and may have better clinical outcomes than MSD-PBSCT; thus, it can be used as first-line treatment for high-risk R/R childhood leukemia.

\footnotetext{
*Correspondence: jizhenyu@zzu.edu.cn; songyongping001@126.com

${ }^{3}$ Department of Hematology, Affiliated Cancer Hospital of Zhengzhou University and Henan Cancer Hospital, Zhengzhou 450000, Henan, China

${ }^{4}$ Henan Academy of Medical and Pharmaceutical Sciences, Zhengzhou University, Zhengzhou 450000, Henan, China

Full list of author information is available at the end of the article
}

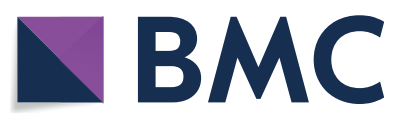

(c) The Author(s) 2020. This article is licensed under a Creative Commons Attribution 4.0 International License, which permits use, sharing, adaptation, distribution and reproduction in any medium or format, as long as you give appropriate credit to the original author(s) and the source, provide a link to the Creative Commons licence, and indicate if changes were made. The images or other third party material in this article are included in the article's Creative Commons licence, unless indicated otherwise in a credit line to the material. If material is not included in the article's Creative Commons licence and your intended use is not permitted by statutory regulation or exceeds the permitted use, you will need to obtain permission directly from the copyright holder. To view a copy of this licence, visit http://creativeco mmons.org/licenses/by/4.0/. The Creative Commons Public Domain Dedication waiver (http://creativecommons.org/publicdomain/ zero/1.0/) applies to the data made available in this article, unless otherwise stated in a credit line to the data. 
Keywords: Prognosis, High-risk refractory and/or relapsed childhood acute leukemia, Allogeneic stem cell transplantation, Matched sibling donors, Alternative donors

\section{Background}

Acute leukemia has become a common malignancy among children, and the incidence has increased gradually. Particularly, acute lymphoblastic leukemia (ALL) has been the most common tumor among children worldwide and in the Middle East [1]. Approximately 98\% of children with ALL can attain remission, and approximately $85 \%$ of patients younger than 18 years with newly diagnosed ALL treated with chemotherapy have a 5 -year survival probability of $90 \%[2,3]$. Although approximately $20 \%$ of patients experience disease relapse [4], the survival rate is still quite poor after relapse, especially among patients with high risk [5], and the long-term survival rate is less than $60 \%$ [6]. Acute myeloid leukemia (AML) is a type of malignant hematological disease with strong heterogeneity and a great variety of effects. Despite great progress in its diagnosis and treatment, the mortality rate of AML remains relatively high and threatens patients' lives severely, and the 5-year overall survival (OS) rate among patients younger than 19 years is approximately $65 \%[7,8]$. In addition, high-risk patients with ALL and AML usually have poorer prognosis with routine treatment. Thus, allogeneic hematopoietic stem cell transplantation (allo-HSCT) is ultimately needed for high-risk patients with refractory and/or relapsed (R/R) disease and may be the only cure.

Allo-HSCT has been widely used as the treatment for hematological diseases. The efficacy of matchingsibling bone marrow transplantation is very significant; however, less than $30 \%$ of patients have matching-sibling donors (MSDs) [9-11] and the collection of bone marrow is relatively cumbersome. Due to the establishment and development of bone marrow donors worldwide, the source of alternative donors (ADs) is relatively broad. With the continuous improvement of conditioning regimen and supportive therapy, the efficacy of $\mathrm{AD}$ peripheral blood stem cell transplantation (AD-PBSCT) has also been continuously improved. Therefore, PBSC may be the main source of stem cells for allo-HSCT in future.

AD-PBSCT as the primary treatment for childhood acute leukemia remains controversial. Our study compared AD-PBSCT with MSD-PBSCT among patients with high-risk $R / R$ childhood leukemia regarding the effects, complications, and influencing factors, providing a theoretical basis for the therapeutic role of $\mathrm{AD}$ PBSCT in this patient population.

\section{Methods}

The study protocol was approved by the ethics committee of our hospital, it was performed in accordance with the Declaration of Helsinki, and the guardians of all the patients provided informed consent for their inclusion at the Affiliated Cancer Hospital of Zhengzhou University. The basic medical record data of 111 patients were retrieved and analyzed (Table 1). All patients were diagnosed and reevaluated according to the National Comprehensive Cancer Network Clinical Practice Guidelines (2012 version) [12, 13]. The definition of high-risk/refractory pediatric acute leukemia is based on the European Society for Blood and Marrow standards [14, 15]. The patients underwent allo-HSCT between October 2006 and July 2019. There were no differences in collection procedure and age between the ADs and MSDs. The inclusion criteria were: (1) acute leukemia (AML or ALL), (2) age $\leq 14$ years at the time of allo-HSCT, (3) high-risk $\mathrm{R} / \mathrm{R}$ diagnosis, and (4) PBSCT performance.

The entire study cohort was divided into the MSD and AD groups based on the donor source. The MSD group (42 patients) matched completely at the human leukocyte antigen (HLA) 10/10 or HLA 6/6 alleles (HLA-DR, HLA-DQ, HLA-A, HLA-B, and HLA-C by high-resolution type; HLA-A, HLA-B, and HLA-C by low-resolution type). The AD group (69 patients) included 32 unrelated and 37 relative haploidentical donors. Nineteen patients matched completely at the HLA10/10 alleles (HLA-DR, HLA-DQ, HLA-A, HLA-B, and HLA-C by high-resolution type) among the unrelated donors.

In the present study, the conditioning regimens among patients were busulfan $(\mathrm{Bu})$ and cyclophosphamide (CTX)-based regimens (Bu/Cy-based, $\mathrm{Bu} 0.8 \mathrm{mg} /$ $\mathrm{kg} \mathrm{q} 6 \mathrm{~h} \times 4$ days, CTX 40-60 $\mathrm{mg} / \mathrm{kg} \times 2$ days) and total body irradiation (TBI) combined with CTX-based regimens (TBI/Cy-based, TBI 4-5 Gy $\times 2$ days, CTX $40-60 \mathrm{mg} / \mathrm{kg} \times 2$ days). To prevent graft-versus-host disease (GVHD), the MSD group was administered cyclosporine A (CsA) combined with a short course of low dose methotrexate and the $\mathrm{AD}$ group was administered mycophenolate mofetil and rabbit anti-human thymocyte immunoglobulin based on MSD. The plasma concentration of CsA was assessed every 3 days and maintained within $200-400 \mathrm{ng} / \mathrm{mL}$. All patients were provided with timely and comprehensive support for symptomatic treatment, including the prevention of infection and hemorrhagic cystitis, the use of granulocyte colony-stimulating factor, and infusion of blood products. 
Table 1 Characteristics of all patients between MSD and AD

\begin{tabular}{|c|c|c|c|c|}
\hline Variables & $\operatorname{MSD}(n=42)$ & $A D(n=69)$ & $x^{2}$ & $P$ value \\
\hline Gender (n, \%) & & & 0.172 & 0.678 \\
\hline Male & $27(64.3)$ & $47(68.1)$ & & \\
\hline Female & $15(35.7)$ & $22(31.9)$ & & \\
\hline Primary disease $(n, \%)$ & & & 0.016 & 0.899 \\
\hline $\mathrm{AML}$ & $22(52.4)$ & $37(53.6)$ & & \\
\hline ALL & $20(47.6)$ & $32(46.4)$ & & \\
\hline Disease status at HSCT (n, \%) & & & 1.873 & 0.392 \\
\hline First $C R$ & $19(45.2)$ & $39(56.5)$ & & \\
\hline Second and other CR & $16(38.1)$ & $18(26.1)$ & & \\
\hline Relapse & $7(16.7)$ & $12(17.4)$ & & \\
\hline Disease status at HSCT (n, \%) & & & 1.332 & 0.248 \\
\hline First $C R$ & $19(45.2)$ & $39(56.5)$ & & \\
\hline Other & $23(54.8)$ & $30(43.5)$ & & \\
\hline Extramedullary infiltration (n, \%) & & & 2.538 & 0.111 \\
\hline Yes & $8(19.0)$ & $6(8.7)$ & & \\
\hline No & $34(81.0)$ & $63(91.3)$ & & \\
\hline Conditioning regimen $(n, \%)$ & & & 0.082 & 0.775 \\
\hline Bu/Cy-based & $30(71.4)$ & $51(73.9)$ & & \\
\hline TBI/Cy-based & $12(28.6)$ & $18(26.1)$ & & \\
\hline Gender of donor-recipient (n, \%) & & & 5.669 & 0.017 \\
\hline Identical & $19(45.2)$ & $47(68.1)$ & & \\
\hline Different & $23(54.8)$ & $22(31.9)$ & & \\
\hline Donor-recipient ABO compatibility ( $n, \%)$ & & & 0.014 & 0.907 \\
\hline Compatible & $19(45.2)$ & $32(46.4)$ & & \\
\hline Incompatible & $23(54.8)$ & $37(53.6)$ & & \\
\hline Abnormal markers & & & NA & NA \\
\hline $\mathrm{t}(9 ; 22)$ & $8(19.0)$ & $13(18.8)$ & & \\
\hline MLL/AF4 & $1(2.4)$ & $3(4.3)$ & & \\
\hline FLT3/ITD & $2(4.8)$ & $1(1.4)$ & & \\
\hline MRD & & & 0.014 & 0.906 \\
\hline Yes & $12(28.6)$ & $19(27.5)$ & & \\
\hline No & $30(71.4)$ & $50(72.5)$ & & \\
\hline $\operatorname{MNC}\left(\times 10^{8} / \mathrm{kg}\right)$ & $11.74(3.98-31.03)$ & $14.57(3.57-47.11)$ & NA & NA \\
\hline CD34 + cells $\left(\times 10^{6} / \mathrm{kg}\right)$ & $5.84(3.43-23.30)$ & $8.33(3.07-35.7)$ & NA & NA \\
\hline Time for implantation of neutrophils (d) & $12(9-19)$ & $13(10-26)$ & NA & NA \\
\hline Time for implantation of PLT(d) & $13(8-30)$ & $13(9-26)$ & NA & NA \\
\hline
\end{tabular}

MSD matched sibling donor, $A D$ alternative donor, $A M L$ acute myeloid leukemia, $A L L$ acute lymphoblastic leukemia, $H S C T$ hematopoietic stem cell transplantation, $C R$ complete remission, $B U$ busulfan, $T B I$ total body irradiation, $C y$ cyclophosphamide, $M R D$ minimal residual disease $M N C$ mononuclear cells, $P L T$ platelet, $N A$ not applicable

The criterion for neutrophil implantation was a neutrophil count of $\geq 0.5 \times 10^{9} /$ Lon the first day and maintained for 3 consecutive days. The criterion for platelet implantation was a platelet count of $\geq 20 \times 10^{9} / \mathrm{L}$ on the first day and maintained for 7 consecutive days without transfusion. After hematopoietic reconstitution, a bone marrow specimen was collected and assessed for evidence of implantation by quantitative polymerase chain reaction assay or sex chromosome analysis. Disease relapse was defined as hematological and clinical recurrence of leukemia. Death other than that due to disease relapse was considered non-relapse mortality. OS was considered the time from the receipt of allo-HSCT to death or the end of follow-up. Disease-free survival (DFS) was considered from the receipt of allo-HSCT to relapse, death, or end of follow-up. Follow-up was performed via outpatient (eight patients) or inpatient (98 patients) visits or via telephone (five patients). Some patients chose to be checked at the 
local hospital due to some special reasons, therefore, we informed the relevant inspection items in advance and acquired the results via telephone.

The classification data were represented as composition ratios. The count data were compared using the Chi squared or the Fisher's exact test, as appropriate. The impacts of factors on survival time were compared using the log-rank test. Univariate analyses of OS and DFS were performed via the Kaplan-Meier method. The Cox regression model was used for multivariate survival analysis. All statistical analyses were performed using GraphPad Prism 7.0 (GraphPad Software, La Jolla, CA, USA) and SPSS 21.0 software (IBM Corp., Armonk, NY, USA). All statistical tests were two-tailed with statistical significance established at $P<0.05$.

\section{Results}

\section{Clinical characteristics}

The clinical characteristics of patients are summarized in Table 1. The MSD group included 27 male and 15 female, 22 of whom were diagnosed with AML and 20 with ALL(of which 19 and 11 cases were refractory, respectively). The AD group included 47 male and 22 female, 37 of whom were diagnosed with AML and 32 with ALL(of which 24 and 12 cases were refractory, respectively). The number of patients who underwent allo-HSCT at the first complete remission (CR1), second, or other CR (all patients who achieved CR except CR1), and relapse were 19,16 , and 7, respectively, in the MSD group and 39, 18 , and 12, respectively, in the AD group. Eight and six patients experienced extramedullary infiltration including relapse before transplantation in the MSD and AD groups, respectively. Seventy-nine patients were evaluated for minimal residual disease (MRD) by flow cytometry, and 31 patients had MRD pre-PBSCT (12 and 19 in the MSD and AD groups, respectively). The median numbers of transfused mononuclear cells were 11.74 (3.98$31.03) \times 10^{8} / \mathrm{kg}$ and $14.57(3.57-47.11) \times 10^{8} / \mathrm{kg}$, and the median numbers of transfused $\mathrm{CD} 34^{+}$cells were 5.84 $(3.43-23.30) \times 10^{6} / \mathrm{kg}$ and $8.33(3.07-35.7) \times 10^{6} / \mathrm{kg}$ in the MSD and AD groups, respectively. There were no significant differences in the basic clinical characteristics between the MSD and AD groups, apart from the gender among recipients.

\section{Engraftment and complications}

Hematopoietic reconstruction was successfully performed in 109 patients, and two patients in the AD group experienced failure due to early graft rejection. The hematopoietic reconstitution rates among patients with AD and MSD were $98.2 \%$ and $100 \%$, respectively. The median times for neutrophil implantation were at day 12 (range, days 9-19) and day 13 (range, days 10-26), respectively, while the corresponding for platelet implantation were days 13 (range, days 8-30) and 13 (range, days 9-26) in the MSD and AD groups, respectively. Acute GVHD (aGVHD) [16] and chronic GVHD (cGVHD) [17] were diagnosed and graded by referring to the Seattle standard and the consensus of the National Institutes of Health [18]. There were no significant differences in the cumulative incidences of aGVHD, cGVHD, invasive pulmonary fungal disease (IPFD), and hemorrhagic cystitis between the MSD and AD groups (all $P>0.05$ ). The cumulative incidence of grade II-IV aGVHD was higher for the AD than for the MSD group, but without statistical significance $(P=0.052)$. The cumulative incidences of Epstein-Barr virus (EBV) and cytomegalovirus (CMV) infections were significantly higher in the AD than in the MSD group (all $P<0.001$ ) (Table 2).

\section{Prognosis in the MSD and AD groups}

Nineteen and 17 patients experienced disease relapse in the MSD and AD groups, respectively. The recurrence rates were significantly higher in the MSD than in the AD group $(P<0.05)$. Sixteen and 14 patients died in the MSD and AD groups, respectively. Thus, the mortality rate was significantly higher for the MSD than the AD group $(P<0.05)$. In addition, the proportion of recurrence among total deaths was significantly higher for the MSD than for the AD group $(P<0.05)$ (Table 2$)$.

\section{Survival analysis in the MSD and AD groups}

We compared the 5-year cumulative survival rates among patients with MSD and AD. The 5-year DFS was significantly higher in the AD than in the MSD group (65.2\% vs. $43.3 \%, P=0.033$ ). The 5 -year OS was also higher in the AD than in the MSD group, but without statistical significance $(71.6 \%$ vs. $53.8 \%, P=0.053)$ (Table 3, Fig. 1 ). Moreover, there were no significant differences in the 5-year DFS and OS among patients with AML and ALL (all $P>0.05$ ) (Fig. 2). There were no significant differences in complications between AML and ALL except for EBV infection $(P=0.026)$ (Table 4$)$.

In addition, we separately assessed the factors affecting the survival of patients in the MSD and AD groups. The 5 -year OS $(78.1 \%$ vs. $30.0 \%, P=0.002)$ and DFS (73.6\% vs. $15.0 \%, P=0.001)$ rates were significantly higher among patients without grade II-IV aGVHD in the AD group than among patients with grade II-IV aGVHD. The 5-year OS of patients who were donorrecipient $\mathrm{ABO}$-compatible was significantly lower than that of those who were $\mathrm{ABO}$-incompatible in the $\mathrm{AD}$ group $(55.6 \%$ vs. $83.0 \%, P=0.047)$. Moreover, the 5 -year OS was significantly lower inpatients who received the TBI/Cy-based regimen than in those who received the $\mathrm{Bu} / \mathrm{Cy}$-based regimen in the $\mathrm{AD}$ group $(58.7 \%$ vs. $77.6 \%$, 
Table 2 Complications and prognosis of all patients between MSD and AD

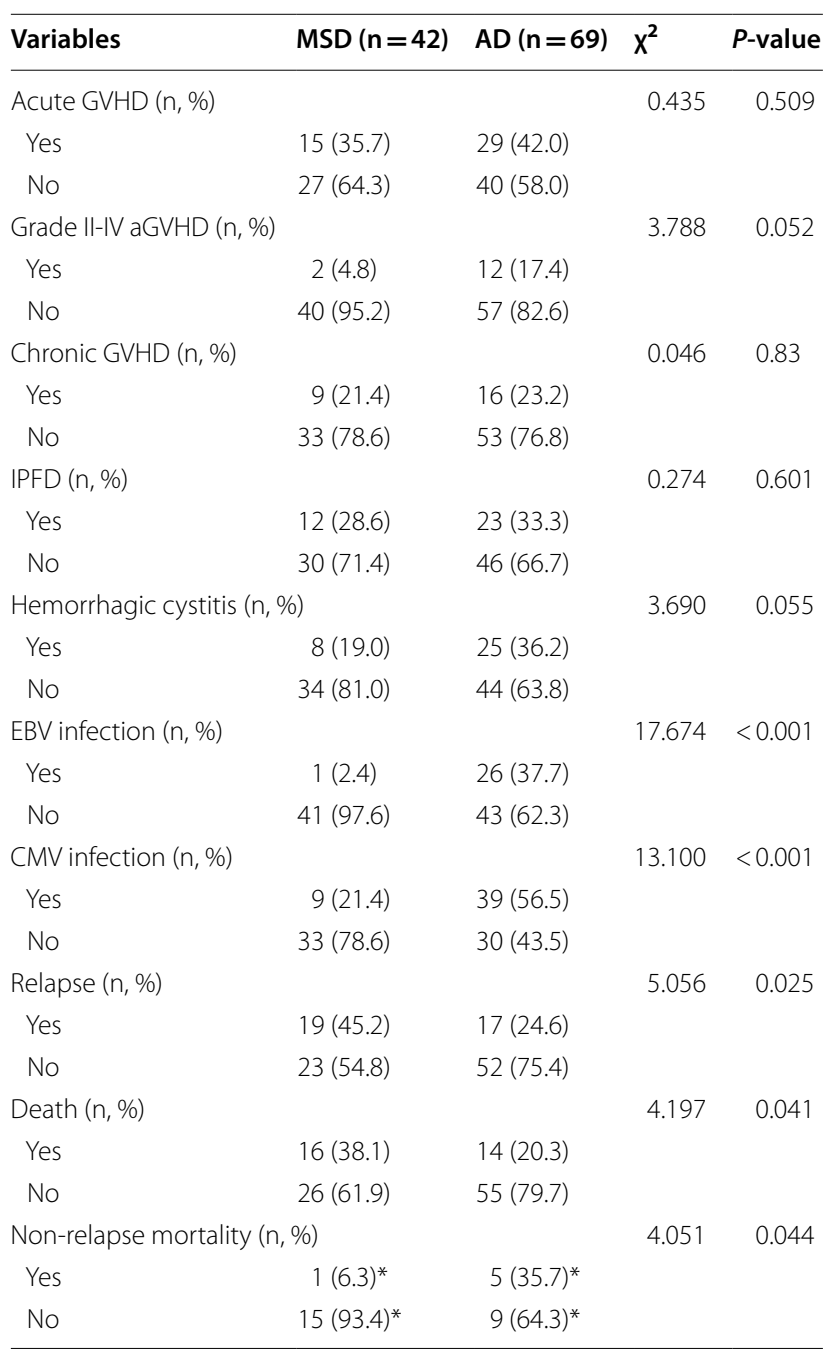

GVHD graft-versus-host disease, IPFD Invasive pulmonary fungal disease, EBV Epstein-Barr virus, CMV Cytomegalovirus; *Non-relapse mortality and relapse mortality as a percentage of total deaths

Table 3 5-year cumulative survival rate of all patients between MSD and AD

\begin{tabular}{llllll}
\hline Variables & \multicolumn{2}{c}{ 5-year cumulative OS } & & \multicolumn{2}{c}{ 5-year cumulative DFS } \\
\cline { 2 - 3 } \cline { 5 - 6 } & Rate (\%) & $\begin{array}{l}\text { Mean time } \\
\text { of survival } \\
\text { (month) }\end{array}$ & & Rate (\%) & $\begin{array}{l}\text { Mean time } \\
\text { of survival } \\
\text { (month) }\end{array}$ \\
\hline MSD & $53.8 \pm 0.09$ & $35.58 \pm 4.62$ & & $43.3 \pm 9.2$ & $30.89 \pm 4.63$ \\
AD & $71.6 \pm 0.07$ & $45.32 \pm 3.37$ & & $65.2 \pm 7.1$ & $42.09 \pm 3.59$ \\
$P$-value & 0.053 & & 0.033 & \\
\hline
\end{tabular}

$P=0.023)$. The 5 -year OS was significantly lower inpatients with CMV infection than in those without in the AD group $(60.9 \%$ vs. $85.0 \%, P=0.033)$. All these factors had no significant effect on the 5-year OS among patients in the MSD group (all $P>0.05$ ). The 5-year DFS rate was significantly higher among the patients who were donorrecipient $\mathrm{ABO}$-compatible than among those who were ABO-incompatible in the MSD group $(67.0 \%$ vs. $27.7 \%$, $P=0.041$ ) (Table 5, Figs. 3 and 4). The other factors had no effect on the survival of patients between the MSD and $\mathrm{AD}$ groups.

\section{Univariate and multivariate Cox regression analyses of all childhood acute leukemia after allo-HSCT}

Univariate Cox regression analysis showed that grade II-IV aGVHD (HR: 3.016, 95\% confidence interval [CI] 1.217-7.473, $P=0.017$ ) influenced the 5-year OS of childhood acute leukemia after allo-HSCT. The donor source (MSD) (HR: 2.035, 95\% CI 1.057-3.920, $P=0.034$ ) and grade II-IV aGVHD (HR: 2.914, 95\% CI 1.261-6.736, $P=0.012$ ) influenced the 5-year DFS.

The multivariate Cox regression analysis showed that grade II-IV aGVHD (HR: 3.524, 95\% CI 1.310-10.988, $P=0.030$ ) was an independent predictor of the 5-year OS for childhood acute leukemia after allo-HSCT. The donor source (MSD) (HR: 2.836, 95\% CI 1.179-6.823, $P=0.020$ ) and grade II-IV aGVHD (HR: 3.731, 95\% CI 1.332-10.454, $P=0.012$ ) were independent predictors of the 5-year DFS.

\section{Discussion}

High-risk R/R childhood acute leukemia has a poor prognosis; allo-HSCT may provide effective treatment for afflicted patients [19-21]. In recent years, AD transplantation has made great progress in the treatment of childhood hematologic diseases [22-26]. Particularly, the 5 -year OS and DFS of patients with childhood high-risk acute leukemia after unrelated bone marrow transplantation can reach up to $75 \%$ and $69.6 \%$, respectively [27]. Our research was mainly focused on AD-PBSCT in the treatment of high-risk $\mathrm{R} / \mathrm{R}$ childhood acute leukemia. In this study, we found that the 5-year OS and DFS rates after AD-PBSCT were $71.6 \%$ and $65.2 \%$, respectively. Its associated long-term survival was similar to that of bone marrow transplantation. In addition, we found that the 5 -year DFS was significantly higher in the AD than in the MSD group ( $65.2 \%$ vs. $43.3 \%, P=0.033)$. The 5 -year OS rate was also higher in the AD than in the MSD group, but without statistical significance $(71.6 \%$ vs. $53.8 \%$, $P=0.053)$. We also found that the recurrence rate and the proportion of recurrence among total deaths were significantly higher in the MSD than in the AD group $(P<0.05)$. Zheng et al. also suggested that for high-risk or advanced childhood acute leukemia, unrelated transplantation yielded a similar long-term survival, but a better anti-leukemic effect than MSD [23]. In terms of survival, 

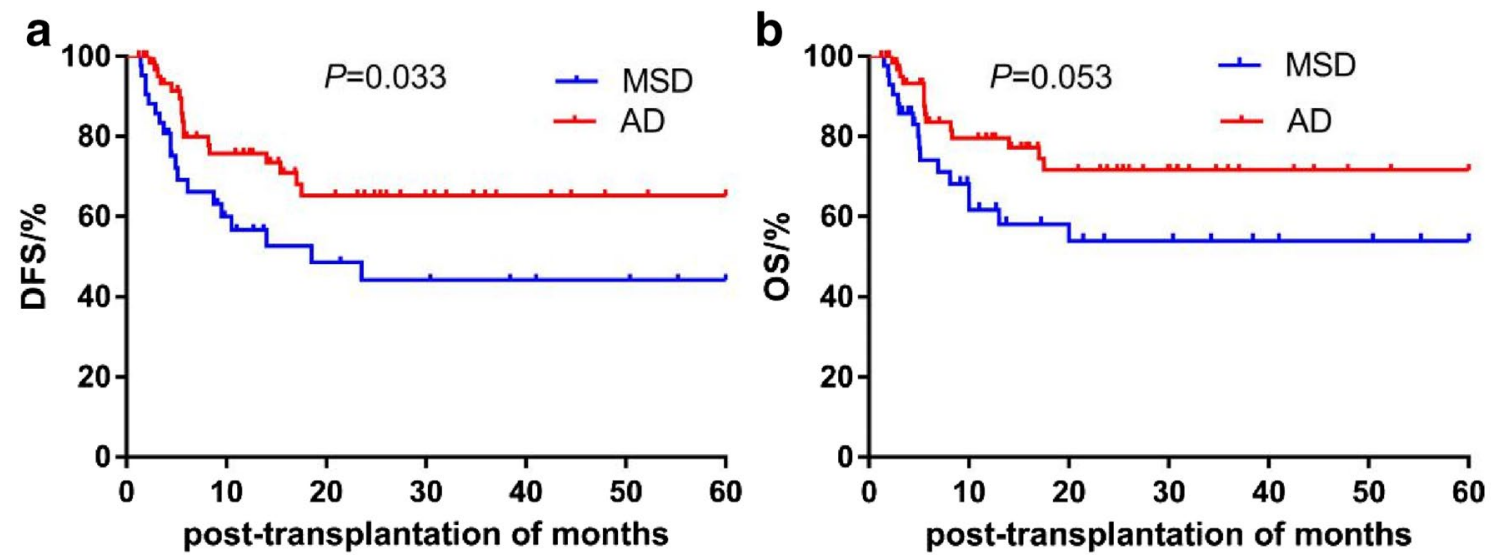

Fig. 1 a Comparison of 5-year DFS rate between MSD and AD; b 5-year OS rate between MSD and AD
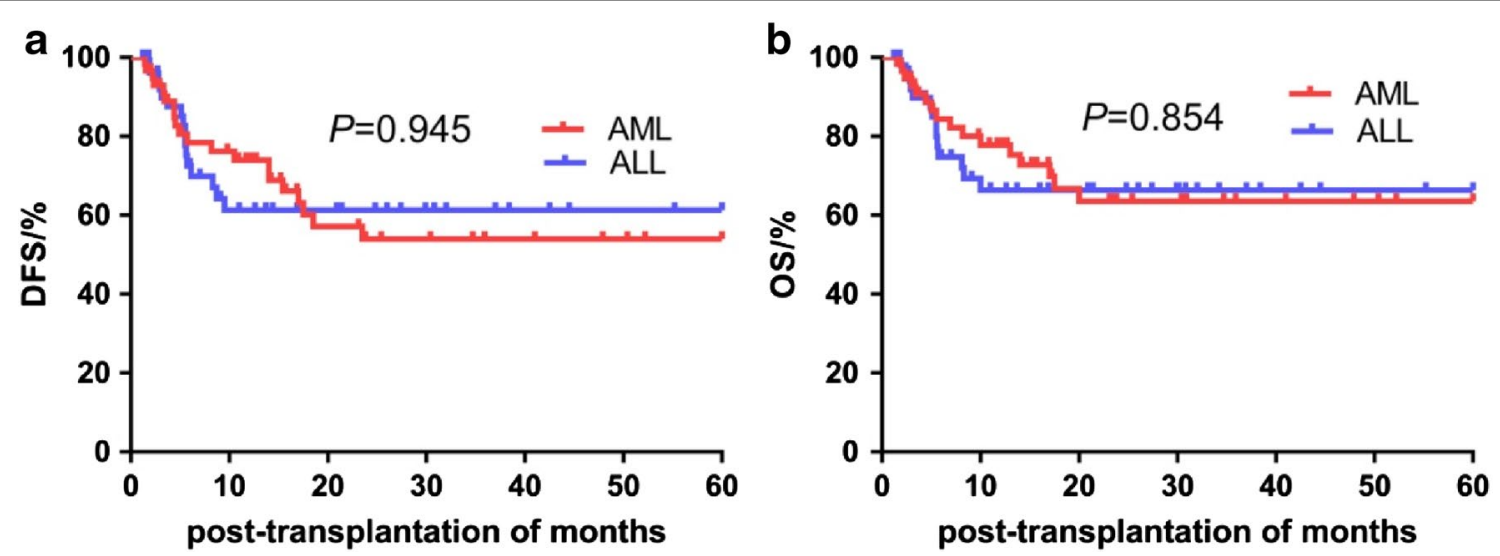

Fig. 2 a Comparison of 5-year DFS rate between AML and ALL; b 5-year OS rate between AML and ALL

Table 4 Complications between AML and ALL

\begin{tabular}{llllllll}
\hline Group & aGVHD & Grade II-IVaGVHD & cGVHD & IPFD & $\begin{array}{l}\text { Hemorrhagic } \\
\text { cystitis }\end{array}$ & EBV infection & CMV infection \\
\hline AML $(n, \%)$ & $23(39)$ & $6(10.2)$ & $12(20.3)$ & $17(28.8)$ & $15(25.4)$ & $9(15.3)$ & $22(37.3)$ \\
ALL $(n, \%)$ & $21(40.4)$ & $8(15.4)$ & $13(25)$ & $18(34.6)$ & $18(34.6)$ & $18(34.6)$ & $26(50)$ \\
$P$ & 1 & 0.568 & 0.651 & 0.545 & 0.307 & 0.026 & 0.186 \\
\hline
\end{tabular}

GVHD graft-versus-host disease, IPFD invasive pulmonary fungal disease, EBV Epstein-Barr virus, CMV cytomegalovirus

AD-PBSCT showed a certain advantage over MSD transplantation. In addition, Keating et al. believed that umbilical cord blood may be also a great alternative cell source when there was no MSD, but further prospective research is needed [28].

Transplantation related complications are the main determinants of survival; particularly, GVHD may be one of the most important factors affecting survival and prognosis [29-31]. We compared the occurrence of complications between the $\mathrm{AD}$ and MSD groups. The cumulative incidence of grade II-IV aGVHD was higher in theAD than in the MSD group, but without statistical significance $(P=0.052)$. Currently, the application of donor regulatory $\mathrm{T}$ cells ameliorates the clinical and histologic symptoms of aGVHD and significantly enhances survival. It prevents aGVHD and it is effective for the treatment of life-threatening complications [31]. The cumulative incidences of EBV and CMV infections were significantly higher in the AD than in the MSD group (all $P<0.001)$. Our study also showed that the 5-year OS was 
Table 5 Factors of affecting 5-year cumulative survival rate between MSD and AD

\begin{tabular}{|c|c|c|c|c|}
\hline \multirow[t]{2}{*}{ Variables } & \multicolumn{2}{|c|}{ 5-year cumulative OS } & \multicolumn{2}{|c|}{ 5-year cumulative DFS } \\
\hline & MSD & $A D$ & MSD & $A D$ \\
\hline \multicolumn{5}{|c|}{ Grade II-IV aGVHD } \\
\hline Yes & $50.0 \pm 35.4$ & $30.0 \pm 17.5$ & $50.0 \pm 35.4$ & $15.0 \pm 13.8$ \\
\hline No & 54.4. \pm 9.0 & $78.1 \pm 6.7$ & $44.4 \pm 9.3$ & $73.6 \pm 7.1$ \\
\hline$P$-value & 0.474 & 0.002 & 0.605 & 0.001 \\
\hline \multicolumn{5}{|c|}{ Donor-recipient ABO compatibility } \\
\hline Compatible & $66.6 \pm 12.8$ & $55.6 \pm 11.4$ & $67.0 \pm 12.8$ & $50.9 \pm 11.6$ \\
\hline Incompatible & $45.9 \pm 11.3$ & $83.0 . \pm 7.1$ & $27.7 \pm 10.9$ & 74.9. \pm 8.5 \\
\hline$P$-value & 0.244 & 0.047 & 0.041 & 0.078 \\
\hline \multicolumn{5}{|c|}{ Conditioning regimen } \\
\hline Bu/Cy-based & $52.3 \pm 10.3$ & $77.6 \pm 7.1$ & $44.1 \pm 10.4^{*}$ & $69.2 \pm 7.9^{*}$ \\
\hline TBI/Cy-based & $60.8 \pm 15.8$ & 58.7. \pm 13.1 & $40.5 \pm 19.6^{*}$ & $58.7 \pm 13.1^{*}$ \\
\hline$P$-value & 0.777 & 0.023 & 0.854 & 0.093 \\
\hline \multicolumn{5}{|l|}{ CMV infection } \\
\hline Yes & $44.4 \pm 18.9$ & $60.9 \pm 9.5$ & $15.6 \pm 14.2^{*}$ & $57.4 \pm 9.7^{*}$ \\
\hline No & $57.2 \pm 9.7$ & $85.0 . \pm 8.2$ & $54 \pm 9.8^{*}$ & $75 \pm 9.9^{*}$ \\
\hline$P$-value & 0.748 & 0.033 & 0.235 & 0.083 \\
\hline
\end{tabular}

* Estimated value censored significantly lower in patients with CMV infection than in those without $(60.9 \%$ vs. $85.0 \%, P=0.033)$ in the $\mathrm{AD}$ group. However, in the MSD group, EBV infection had no significant effect on the survival in the AD and MSD groups. Previous studies have shown that CMV reactivation remains a risk factor for poor post-transplantation outcomes and there are no preventive measures specifically for the recurrence of hematological diseases [32], but the impact of CMV infection on survival after transplantation remains controversial [33]. In addition, rituximab and donor lymphocyte infusion are established as successful options for EBV infection [34]. Therefore, EBV and CMV infections do not always threaten the lives of patients. In this study, there were no significant differences in the incidences of IPFD, hemorrhagic cystitis, cGVHD, and other complications.

We assessed the factors affecting the survival of patients in the MSD and AD groups. We found that the 5 -year OS (78.1\% vs. $30.0 \%, P=0.002)$ and DFS $(73.6 \%$ vs. $15.0 \%, P=0.001)$ rates were significantly higher among patients without grade II-IV aGVHD in the AD group than among patients with grade II-IV aGVHD. This is consistent with previous studies that showed that grade II-IV aGVHD is a key factor that affects survival and
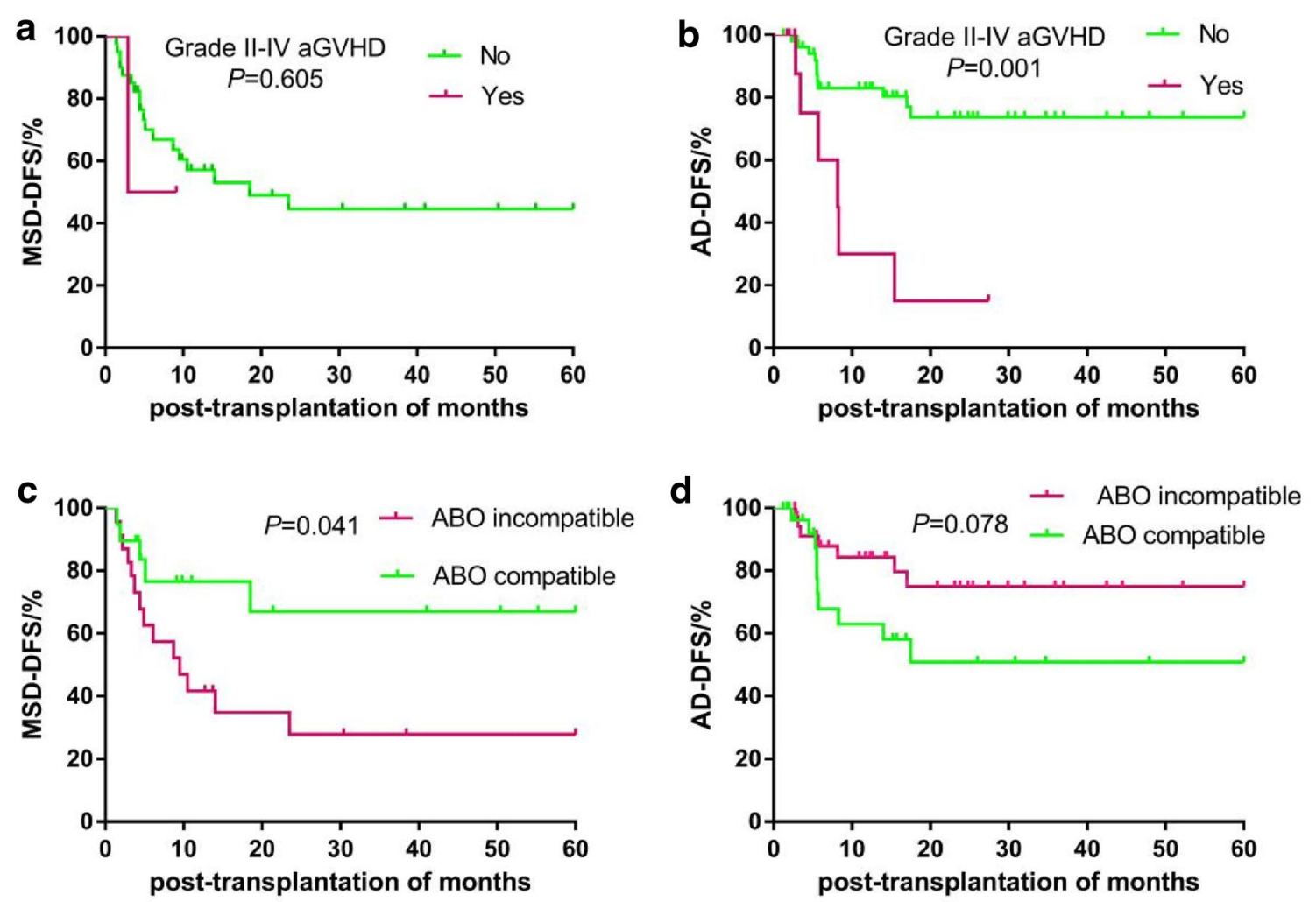

Fig. 3 The impacts of grade II-IV aGVHD (a, $\mathbf{b})$ and donor-recipient ABO compatibility $(\mathbf{c}, \mathbf{d})$ on 5-year DFS between MSD and AD in one hundred eleven children with acute leukemia 

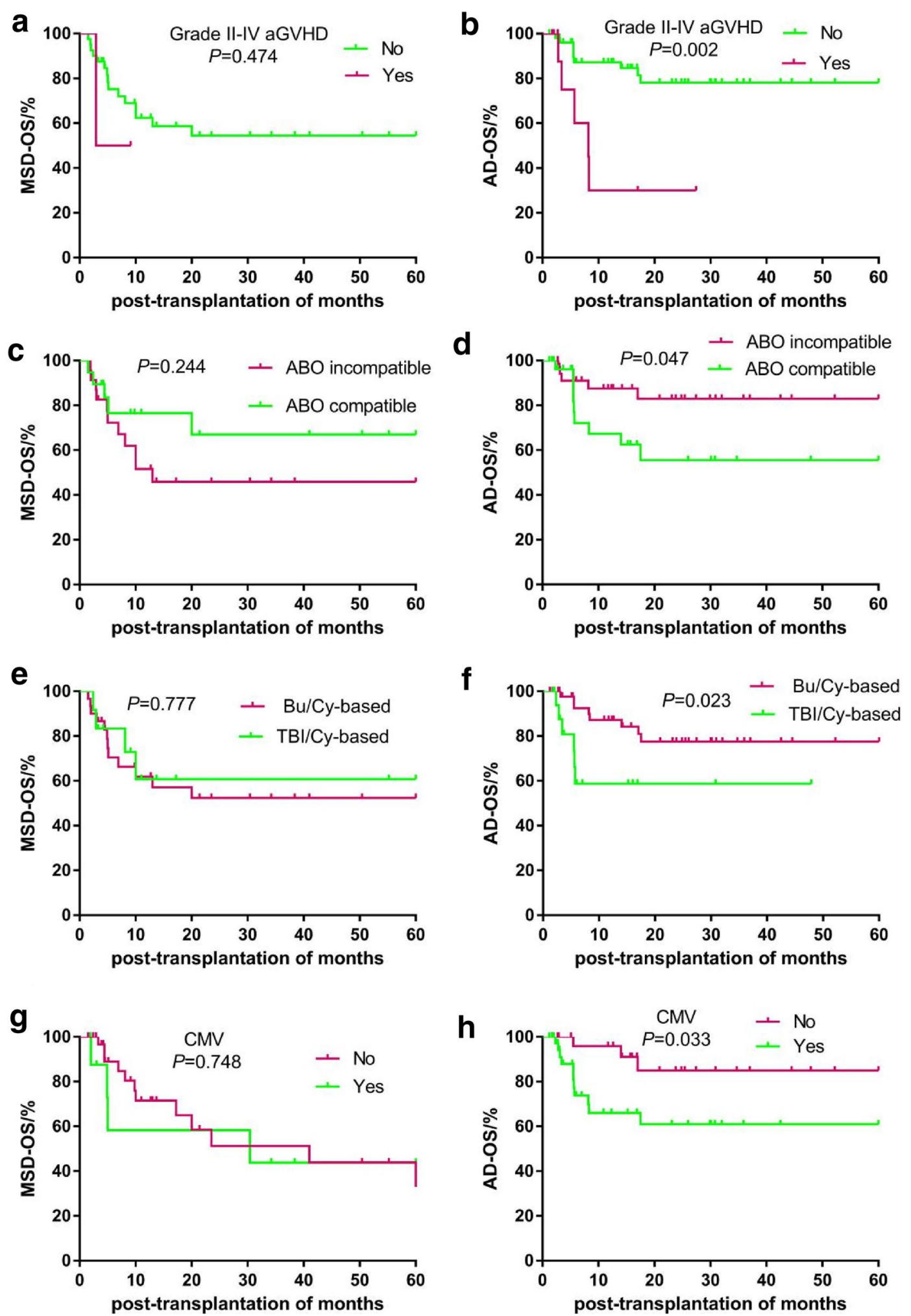

Fig. 4 The factors of affecting 5-year OS rate between MSD and AD in one hundred eleven childhood acute leukemia; (a, b grade II-IV aGVHD; c, $\mathbf{d}$ donor-recipient $\mathrm{ABO}$ compatibility; $\mathbf{e}$, $\mathbf{f}$ conditioning regimen; $\mathbf{g}, \mathbf{h}$ CMV infection) 
prognosis among patients [35-38]. The 5-year OS rate was significantly lower among donor-recipient $\mathrm{ABO}$ compatible than among $\mathrm{ABO}$-incompatible patients in the $\operatorname{AD}$ group $(55.6 \%$ vs. $83.0 \%, P=0.047)$. However, the 5 -year DFS rate was significantly higher among donorrecipient $\mathrm{ABO}$-compatible than among $\mathrm{ABO}$-incompatible patients in the MSD group $(67.0 \%$ vs. $27.7 \%$, $P=0.041)$. At present, the impact of donor and recipient $\mathrm{ABO}$ statuses on the efficacy of transplantation among leukemia patients remain controversial. Wang et al. showed that donor-recipient $\mathrm{ABO}$ in compatibility was significantly correlated with delayed platelet recovery among older donors and higher transplantation related mortality rates and higher rates of grade III aGVHD [39]. Nicolas et al. revealed that the major ABO incompatibility was associated with a significantly low recurrence rate $(\mathrm{HR}=0.65, P=0.04)[40]$. However, some other studies showed that donor-recipient $\mathrm{ABO}$ mismatch had no significant effects on major survival outcomes after alloHSCT, such as the incidence of GVHD, rates of relapse and mortality, DFS, and OS. Also, donor-recipient ABO incompatibility was not associated with delayed platelet and neutrophil engraftment after allo-HSCT [41, 42]. There was no evidence of a substantial effect of donorrecipient $\mathrm{ABO}$ incompatibility on the outcome of alloHSCT among patients with leukemia [43]. The Japanese Marrow Donor Program reported that the 1-year survival rate after $\mathrm{ABO}$-matched transplantation was $63 \%$, compared with $57 \%$ after minor and major $\mathrm{ABO}$ mismatched transplantation. Therefore, donor-recipient ABO matching has a modest effect on survival [44]. The 5-year OS rate was significantly lower among patients who received the $\mathrm{TBI} / \mathrm{Cy}$-based regimen $(58.7 \%$ vs. $77.6 \%, P=0.023)$ than among those who received the $\mathrm{Bu} / \mathrm{Cy}$-based regimen in the AD group. This may be related to the application of TBI to increase the risk of grade II-IV aGVHD, which in turn affects the survival of patients [45, 46]. Grade II-IV aGVHD, conditioning regimen, and donorrecipient $\mathrm{ABO}$ status had no significant effect on 5-year OS among patients in the MSD group (all $P>0.05$ ).

In addition, we comprehensively assessed all children with leukemia. The univariate Cox regression analysis showed that grade II-IV aGVHD (HR: 3.016, 95\% CI $1.217-7.473, P=0.017)$ was a factor that influenced the 5 -year OS of childhood acute leukemia after alloHSCT. This result is consistent with the factor affecting AD transplantation. The donor source (MSD) (HR: $2.035,95 \%$ CI $1.057-3.920, P=0.034$ ) and grade II-IV aGVHD (HR: 2.914, 95\% CI 1.261-6.736, $P=0.012$ ) were factors that influenced the 5-year DFS. The multivariate Cox regression analysis showed that grade II-IV aGVHD (HR: 3.524, 95\% CI 1.310-10.988, $P=0.030$ ) was an independent risk factor of 5-year OS. The donor source (MSD) (HR: 2.836, 95\% CI 1.179-6.823, $P=0.020$ ) and grade II-IV aGVHD (HR: 3.731, 95\% CI $1.332-10.454, P=0.012)$ were independent predictors of 5-year DFS. Chen et al. also showed that grade III-IV aGVHD may be related to worse survival, but cGVHD had no significant influence on DFS or OS [37]. Tomizawa et al. also showed that grade II-IV aGVHD $(P=0.049)$ was related to inferior OS [47]. In our study, the disease status at HSCT had no significant effect on survival. Montoro et al. found that there were no obvious differences in OS, DFS, and recurrence rates between patients transplanted in CR1 and CR2. However, patients with high-risk cytogenetics at diagnosis tended to have significantly worse prognoses [48]. In addition, a previous study showed that the 3-year OS rates among patients who underwent transplants at CR1 and CR2 were $73 \%$ and $25 \%$, respectively. This study supported the notion that allo-HSCT maybe a suitable treatment for high-risk AML at CR1 [19].

A previous study has reported that the 3-year OS rates among patients who underwent allo-HSCT and those who only underwent salvage chemotherapy were $67 \%$ and $12 \%$, respectively. In addition, the 5 -year OS rates among patients who underwent allo-HSCT and those who only underwent salvage chemotherapy were $44 \%$ and $4 \%$, respectively $(P<0.001)$. Allo-HSCT remains the most promising treatment option among patients with refractory AML [49]. Xue et al. found that haploidentical HSCT (haplo-HSCT) only showed a significant survival advantage among high-risk ALL patients. The authors posited that haplo-HSCT can be used as an alternative treatment modality for high-risk ALL patients [20]. A study conducted in China showed that allo-HSCT can be recommended as treatment for intermediate-risk and high-risk AML-CR1, some low-risk AML-CR1, $\mathrm{Ph}^{+} \mathrm{ALL}$, high-risk ALL, and adult standard-risk ALL-CR1. The effects of AD-HSCT and MSD-HSCT are comparable in China [50]. Haplo-HSCT can achieve similar results as MSD-HSCT in high-risk ALL patients with CR1, and this transplant maybe an effective option for post-remission treatment of high-risk ALL-CR1 patients without MSD $[21,50]$.

\section{Conclusions}

AD-PBSCT is effective for high-risk $R / R$ childhood leukemia. The incidence of complications is low, and these complications have no significant effect on survival. These results all show that AD-PBSCT may have better clinical outcomes than MSD-PBSCT. Overall, ADPBSCT can be used as first-line treatment for high-risk $\mathrm{R} / \mathrm{R}$ childhood leukemia; its efficacy and safety may even be better than those of MSD transplantation. 


\begin{abstract}
Abbreviations
AD: Alternative donor; ALL: Acute lymphoblastic leukemia; AML: Acute myeloid leukemia; DFS: Disease-free survival; DLI: Donor lymphocyte infusion; GVHD: Graft-versus-host disease; aGVHD: Acute graft-versus-host disease; cGVHD: Chronic graft-versus-host disease; IPFD: Invasive pulmonary fungal disease; MSD: Matching-sibling donor; OS: Overall survival; TBI: Total body irradiation; CMV: Cytomegalovirus; CR: complete remission; CsA: Cyclosporine A; EBV: Epstein-Barr virus; HSCT: Hematopoietic stem cell transplantation; haplo-HSCT: Haploidentical hematopoietic stem cell transplantation.
\end{abstract}

\section{Acknowledgements}

We would like to thank all patients for their cooperation and the Department of Hematology, Affiliated Cancer Hospital and Henan Cancer Hospital, School of Basic Medical Sciences of Zhengzhou University for providing administrative support and provision of study patients.

\section{Authors' contributions}

$B Z, J Z$, and YS designed the study and drafted the manuscript. All authors participated in the revision of the manuscript. All authors read and approved the final manuscript.

\section{Funding}

The study was partly supported by the Affiliated Cancer Hospital of Zhengzhou University, Zhengzhou, China.

\section{Availability of data and materials}

All data generated or analyzed during this study are included in this published article.

\section{Ethics approval and consent to participate}

The study protocol was approved by the ethics committee, and guardians of all the patients provided informed consent for their inclusion at the Affiliated Cancer Hospital of Zhengzhou University.

\section{Consent for publication}

The participants' legal guardians provided informed consent for the publication of the study.

\section{Competing interests}

The authors declare that they have no competing interests.

\section{Author details}

${ }^{1}$ School of Basic Medical Sciences, Zhengzhou University, Zhengzhou 450000, Henan, China. ${ }^{2}$ Academy of Medical Sciences, Zhengzhou University, Zhengzhou 450000, Henan, China. ${ }^{3}$ Department of Hematology, Affiliated Cancer Hospital of Zhengzhou University and Henan Cancer Hospital, Zhengzhou 450000, Henan, China. ${ }^{4}$ Henan Academy of Medical and Pharmaceutical Sciences, Zhengzhou University, Zhengzhou 450000, Henan, China.

Received: 14 February 2020 Accepted: 23 March 2020

Published online: 06 April 2020

\section{References}

1. An Q, Fan $\mathrm{CH}$, Xu SM. Recent perspectives of pediatric leukemia-an update. Eur Rev Med Pharmacol. 2017;21:31-6.

2. Möricke A, Zimmermann M, Valsecchi MG, Stanulla M, Biondi A, Mann $G$, et al. Dexamethasone vs. prednisone in induction treatment of pediatric ALL: results of the randomized trial AIEOP-BFM ALL 2000. Blood. 2016;127:2101-12.

3. Pieters R, Groot-Kruseman HD, Velden V, Fiocco M, Berg H, Bont ED, et al. Successful therapy reduction and intensification for childhood acute lymphoblastic leukemia based on minimal residual disease monitoring: Study ALL 10 from the Dutch Childhood Oncology Group. J Clin Oncol. 2016:34:2591-601.

4. van den Berg H, de Groot-Kruseman HA, Damen-Korbijn CM, de Bont ESJM, Schouten-van Meeteren AYN, Hoogerbrugge PM. Outcome after first relapse in children with acute lymphoblastic leukemia: A report based on the Dutch Childhood Oncology Group (DCOG) relapse all 98 protocol. Pediatr Blood Cancer. 2011;57:210-6.

5. Oskarsson T, Söderhäll S, Arvidson J, Forestier E, Montgomery S, Bottai $M$, et al. Relapsed childhood acute lymphoblastic leukemia in the Nordic countries: prognostic factors, treatment and outcome. Haematologica. 2016;101:68-76.

6. Parker C, Waters R, Leighton C, Hancock J, Sutton R, Moorman AV, et al. Effect of mitoxantrone on outcome of children with first relapse of acute lymphoblastic leukaemia (ALL R3): an open-label randomised trial. Lancet. 2010;376:2009-17.

7. Zhang N, Chen Y, Lou S, Shen Y, Deng J. A six-gene-based prognostic model predicts complete remission and overall survival in childhood acute myeloid leukemia. Onco Targets Ther. 2019;12:6591-604.

8. Lim SH, Dubielecka PM, Raghunathan VM. Molecular targeting in acute myeloid leukemia. J Transl Med. 2017;15:183.

9. Riezzo I, Pascale N, La Russa R, Liso A, Salerno M, Turillazzi E. Donor selection for allogenic hemopoietic stem cell transplantation: clinical and ethical considerations. Stem Cells Int. 2017;2017:5250790.

10. Tiercy JM, Nicoloso G, Passweg J, Schanz U, Seger R, Chalandon Y, et al. The probability of identifying a 10/10 HLA allele-matched unrelated donor is highly predictable. Bone Marrow Transplant. 2007;40:515-22.

11. Eapen M, Rubinstein P, Zhang MJ, Camitta BM, Stevens C, Cairo MS, et al. Comparable long-term survival after unrelated and HLA-matched sibling donor hematopoietic stem cell transplantations for acute leukemia in children younger than 18 months. J Clin Oncol. 2006;24:145-51.

12. Alvarnas JC, Brown PA, Aoun P, Ballen KK, Bellam N, Blum W, et al. Acute lymphoblastic leukemia. J Natl Compr Cancer Netw. 2012;10:858-914.

13. O'Donnell MR, Abboud CN, Altman J, Appelbaum FR, Arber DA, Attar E, et al. NCCN Clinical Practice Guidelines Acute myeloid leukemia. J Natl Compr Cancer Netw. 2012;10:984-1021.

14. Gibson BES, Sauer MG, Amrolia P. Acute myeloid leukemia in children. In: Carreras E, Dufour C, Mohty M, et al. editors. The EBMT handbook: hematopoietic stem cell transplantation and cellular therapies. 2019. p. 523-30.

15. Peters $C$, Locatelli F, Bader P. Acute lymphoblastic leukemia in children and adolescents. In: Carreras E, Dufour C, Mohty M, et al. editors. The EBMT Handbook: hematopoietic stem cell transplantation and cellular therapies. 2019. p. 539-45.

16. Przepiorka D, Weisdorf D, Martin P, Klingemann HG, Beatty P, Hows J, et al. 1994 consensus conference on acute GVHD grading. Bone Marrow Transplant. 1995;15:825-8.

17. Shulman HM, Sullivan KM, Weiden PL, McDonald GB, Striker GE, Sale GE, et al. Chronic graft-versus-host syndrome in man along-term clinicopathologic study of 20 Seattle patients. Am J Med. 1980;69:204-17.

18. Jagasia MH, Greinix HT, Arora M, Williams KM, Wolff D, Cowen EW, et al. National institutes of health consensus development project on criteria for clinical trials in chronic graft-versus-host disease: I. The 2014 Diagnosis and Staging Working Group report. Biol Blood Marrow Transplant. 2015;2015(21):389-401.

19. Hyakuna N, Hashii Y, Ishida H, Umeda K, Takahashi Y, Nagasawa M, et al. Retrospective analysis of children with high-risk acute myeloid leukemia who underwent allogeneic hematopoietic stem cell transplantation following complete remission with initial induction chemotherapy in the AML-05 clinical trial. Pediatr Blood Cancer. 2019;66:e27875.

20. Xue YJ, Cheng YF, Lu AD, Wang Y, Zuo YX, Yan CH, et al. Allogeneic hematopoietic stem cell transplantation, especially haploidentical, may improve long-term survival for high-risk pediatric patients with Philadelphia chromosome-positive acute lymphoblastic leukemia in the tyrosine kinase inhibitor era. Biol Blood Marrow Transplant. 2019;25:1611-20.

21. Wang Y, Liu QF, Xu LP, Liu KY, Zhang XH, Ma X, et al. Haploidentical versus matched-sibling transplant in adults with Philadelphia-negative high-risk acute lymphoblastic leukemia: a biologically phase III randomized study. Clin Cancer Res. 2016;22:3467-76.

22. Satwani P, Sather H, Ozkaynak F, Heerema NA, Schultz KR, Sanders J, et al. Allogeneic bone marrow transplantation in first remission for children with ultra-high-risk features of acute lymphoblastic leukemia: a children's oncology group study report. Biol Blood Marrow Transplant. 2007:13:218-27.

23. Zheng C, Zhu X, Tang B, Yao W, Song K, Tong J, et al. Comparative analysis of unrelated cord blood transplantation and HLA-matched sibling 
hematopoietic stem cell transplantation in children with high-risk or advanced acute leukemia. Ann Hematol. 2015;94:473-80.

24. Marshall GM, Dalla Pozza L, Sutton R, Ng A, de Groot-Kruseman HA, van der Velden VH, et al. High-risk childhood acute lymphoblastic leukemia in first remission treated with novel intensive chemotherapy and allogeneic transplantation. Leukemia. 2013;27:1497-503.

25. Shaw PJ, Kan F, Woo Ahn K, Spellman SR, Aljurf M, Ayas M, et al. Outcomes of pediatric bone marrow transplantation for leukemia and myelodysplasia using matched sibling, mismatched related, or matched unrelated donors. Blood. 2010;116:4007-15.

26. Wilhelmsson M, Glosli H, Ifversen M, Abrahamsson J, Winiarski J, Jahnukainen $\mathrm{K}$, et al. Long-term health outcomes in survivors of childhood AML treated with allogeneic HSCT: a NOPHO-AML Study. Bone Marrow Transplant. 2019;54:726-36.

27. Sakaguchi $\mathrm{H}$, Watanabe N, Matsumoto K, Yabe H, Kato S, Ogawa A, et al. Comparison of donor sources in hematopoietic stem cell transplantation for childhood acute leukemia: a nationwide retrospective study. Biol Blood Marrow Transplant. 2016;22:2226-34.

28. Keating AK, Langenhorst J, Wagner JE, Page KM, Veys P, Wynn RF, et al. The influence of stem cell source on transplant outcomes for pediatric patients with acute myeloid leukemia. Blood Adv. 2019;3:1118.

29. Jacobsohn DA, Arora M, Klein JP, Hassebroek A, Flowers ME, Cutler CS, et al. Risk factors associated with increased non-relapse mortality and with poor overall survival in children with chronic graft-versus-host disease. Blood. 2011;118:4472-9.

30. Schoemans HM, Lee SJ, Ferrara JL, Wolff D, Levine JE, Schultz KR, et al. EBMT-NIH-CIBMTR Task Force position statement on standardized terminology and guidance for graft-versus-host disease assessment. Bone Marrow Transplant. 2018;53:1401-15.

31. Riegel C, Boeld TJ, Doser K, Huber E, Hoffmann P, Edinger M. Efficient treatment of murine acute $\mathrm{GvHD}$ by in vitro expanded donor regulatory $\mathrm{T}$ cells. Leukemia. 2020;34:895-908.

32. Teira P, Battiwalla M, Ramanathan M, Barrett AJ, Ahn KW, Chen M, et al. Early cytomegalovirus reactivation remains associated with increased transplant-related mortality in the current era: a CIBMTR analysis. Blood. 2016;127:2427-38.

33. Giménez E, Torres I, Albert E, Piñana JL, Hernández-Boluda JC, Solano C, et al. Cytomegalovirus (CMV) infection and risk of mortality in allogeneic hematopoietic stem cell transplantation (Allo-HSCT): a systematic review, meta-analysis, and meta-regression analysis. Am J Transplant. 2019;19:2479-94

34. Burns DM, Ryan GB, Harvey CM, Nagy E, Hughes S, Murray PG, et al. Nonuniform in vivo expansion of Epstein-Barr virus-specific T-cells following donor lymphocyte infusion for post-transplant lympho proliferative disease. Front Immunol. 2019;10:2489.

35. Ruggeri A, Labopin M, Savani B, Paviglianiti A, Blaise D, Volt F, et al. Hematopoietic stem cell transplantation with unrelated cord blood or haploidentical donor grafts in adult patients with secondary acute myeloid leukemia, a comparative study from Eurocord and the ALWP EBMT. Bone Marrow Transplant. 2019;54:1987-94.

36. Qayed M, Wang T, Hemmer MT, Spellman S, Arora M, Couriel D, et al. Influence of age on acute and chronic GVHD in children undergoing HLAidentical sibling bone marrow transplantation for acute leukemia: implications for prophylaxis. Biol Blood Marrow Transplant. 2018;24:521-8.

37. Chen YB, Wang T, Hemmer MT, Brady C, Couriel DR, Alousi A, et al. GvHD after umbilical cord blood transplantation for acute leukemia: an analysis of risk factors and effect on outcomes. Bone Marrow Transplant. 2017:52:400-8.
38. Vignon M, Andreoli A, Dhédin N, Lengliné E, Masson E, Robin M, et al. Graft-versus-host disease in adolescents and young adults (15-24 years old) after allogeneic hematopoietic stem cell transplantation for acute leukemia in first complete remission. J Adolesc Young Adult Oncol. 2017:6:299-306.

39. Wang Y, Wu DP, Liu QF, Xu LP, Liu KY, Zhang XH, et al. Donor and recipient age, gender and $\mathrm{ABO}$ incompatibility regardless of donor source: validated criteria for donor selection for haematopoietic transplants. Leukemia. 2018;32:492-8.

40. Blin N, Traineau R, Houssin S, de Peffault Latour R, Petropoulou A, Robin $\mathrm{M}$, et al. Impact of donor-recipient major ABO mismatch on allogeneic transplantation outcome according to stem cell source. Biol Blood Marrow Transplant. 2010;16:1315-23.

41. Ciftciler R, Goker H, Buyukasık Y, Karaagac T, Aksu S, Tekin F, et al. Impact of $\mathrm{ABO}$ blood group incompatibility on the outcomes of allogeneic hematopoietic stem cell transplantation. Transfus Apher Sci. 2019. https ://doi.org/10.1016/j.transci.2019.06.024.

42. Booth GS, Gehrie EA, Bolan CD, Savani BN. Clinical guide to ABOincompatible allogeneic stem cell transplantation. Biol Blood Marrow Transplant. 2013;19:1152-8.

43. Seebach JD, Stussi G, Passweg JR, Loberiza FR Jr, Gajewski JL, Keating A, et al. $\mathrm{ABO}$ blood group barrier in allogeneic bone marrow transplantation revisited. Biol Blood Marrow Transplant. 2005;11:1006-13.

44. Kollman C, Spellman SR, Zhang MJ, Hassebroek A, Anasetti C, Antin JH, et al. The effect of donor characteristics on survival after unrelated donor transplantation for hematologic malignancy. Blood. 2016;127:260-7.

45. Wang F, Cai B, Wang L, Gu Z, Luo L, Wei H, et al. Risk factors for acute graftversus-host disease after allogeneic haematopoietic stem cell transplantation: a Single-Center Experience. Ann Transplant. 2017;22:58-65.

46. Szmit Z, Kałwak K, Król A, Mielcarek-Siedziuk M, Salamonowicz M, Frączkiewicz J, et al. Premature cyclosporine cessation and TBI-containing conditioning regimen increase the risk of acute GvHD in children undergoing unrelated donor hematopoietic stem cell transplantation. Adv Clin Exp Med. 2019;28:1 185-92.

47. Tomizawa D, Yoshida M, Kondo T, Miyamura T, Taga T, Adachi S, et al. Allogeneic hematopoietic stem cell transplantation for children and adolescents with high-risk cytogenetic AML: distinctly poor outcomes of FUS-ERG-positive cases. Bone Marrow Transplant. 2019;54:393-401.

48. Montoro J, Ceberio I, Hilden P, Maloy MA, Barker J, Castro-Malaspina $\mathrm{H}$, et al. Ex vivo T cell-depleted hematopoietic stem cell transplantation for adult patients with acute myelogenous leukemia in first and second remission: long-term disease-free survival with a significantly reduced risk of graft-versus-host disease. Biol Blood Marrow Transplant. 2020;26:323-32.

49. Ciftciler R, Demiroglu H, Buyukasık Y, Aladag E, Aksu S, Haznedaroglu IC, et al. Efficacy and feasibility of allogeneic hematopoietic stem-cell transplantation in the treatment of refractory acute myeloid leukemia. Clin Lymphoma Myeloma Leuk. 2019;19:177-82.

50. Xu L, Chen H, Chen J, Han M, Huang H, Lai Y, et al. The consensus on indications, conditioning regimen, and donor selection of allogeneic hematopoietic cell transplantation for hematological diseases in Chinarecommendations from the Chinese Society of Hematology. J Hematol Oncol. 2018;11:33.

\section{Publisher's Note}

Springer Nature remains neutral with regard to jurisdictional claims in published maps and institutional affiliations. 